\title{
Combined gastrin and epidermal growth factor treatment induces islet regeneration and restores normoglycaemia in C57B16/J mice treated with alloxan
}

\author{
I. Rooman • L. Bouwens \\ Department of Cell Differentiation, Diabetes Research Center, Vrije Universiteit Brussel, Brussels, Belgium
}

\begin{abstract}
Aims/hypothesis. Increasing beta-cell mass and/or function could restore glucose homeostasis in diabetes mellitus. Hitherto, trophic factors for beta-cell regeneration after toxic events have been difficult to identify. We evaluated the application of gastrin and epidermal growth factor after alloxan-induced pancreatic beta-cell damage.

Methods. After alloxan treatment $(70 \mathrm{mg} / \mathrm{kg})$, mice were implanted with Alzet osmotic minipumps releasing gastrin and epidermal growth factor for one week. We monitored glycaemia, did histological analyses of the pancreata and quantified pancreatic beta-cell mass and insulin content.

Results. Alloxan treatment alone resulted in a persisting hyperglycaemic state. Combined gastrin and epidermal growth factor treatment restored normoglycaemia in 3 days, an effect which seemed permanent. Glucose tolerance tests showed normal glucose re-
\end{abstract}

sponsiveness. Gastrin on its own and epidermal growth factor on its own did not alleviate hyperglycaemia. Islet mass, islet density and pancreatic insulin content were higher in mice treated with gastrin and epidermal growth factor than in untreated mice with persisting hyperglycaemia. In normoglycaemic control mice treatment with gastrin and epidermal growth factor did not affect these parameters. We detected transitional cytokeratin-positive ductal to endocrine insulinexpressing cells and noted increased ductal but not beta-cell proliferation.

Conclusions/interpretation. Our results show that combined treatment with gastrin and epidermal growth factor can induce sufficient regeneration of a functional islet mass to restore glucose homeostasis. [Diabetologia (2004) 47:259-265]

Keywords Pancreas - Diabetes mellitus - Islets · Ductal $\cdot$ Regeneration $\cdot$ Gastrin $\cdot$ Epidermal growth factor - Alloxan
Islet transplantation can restore glycaemic control and prevent chronic complications from diabetes [1, 2]. However, it is hampered by the shortage of donors and

Received: 6 June 2003 / Revised: 29 September 2003

Published online: 10 December 2003

(C) Springer-Verlag 2003

\author{
L. Bouwens ( $)$ \\ Department of Cell Differentiation, Diabetes Research Center, \\ Vrije Universiteit Brussel, Laarbeeklaan 103, 1090 Brussels, \\ Belgium \\ E-mail: lucbo@expa.vub.ac.be
}

Abbreviations: BrdU, bromodeoxyuridine - EGF, epidermal growth factor the need for life-long immunosuppressive therapy. Therefore, there is a growing interest in regenerative medicine, which in the case of diabetes aims at restoring a patient's own insulin-producing cell mass [3]. Understanding the mechanisms of islet regeneration could also help provide larger numbers of beta cells for transplantation. In rodents, the beta-cell mass can expand considerably as a result of proliferation and differentiation of precursor cells in the exocrine pancreas, i.e. by the process of neogenesis [4]. Previously we reported that gastrin can stimulate the formation of new islet cells in a condition where the exocrine pancreas was damaged (by duct ligation) [5]. In that model the exocrine cells changed their phenotypic state (acinoductal transdifferentiation) and became respon- 
sive to gastrin by inducing the gastrin receptor [6] However, in the unligated pancreas, gastrin had no effect on the beta-cell mass, indicating that additional factors are required [5]. For the present study we wanted to avoid the use of duct ligation and test the combination of gastrin with another factor, namely epidermal growth factor (EGF). The choice of EGF was based on a previous study where an increase in islet mass was observed in double transgenic, normoglycaemic mice expressing TGF- $\alpha$ and gastrin in the pancreas [7]. EGF acts via the same receptor as TGF$\alpha$ and was preferred for practical reasons. In addition, we treated alloxan-diabetic mice to test the effect of both factors on glycaemia as well as on islet regeneration.

\section{Materials and methods}

Animals. In this study, male C57B16/J mice of 9 to 11 weeks of age with a mean body weight of $27 \mathrm{~g}$ (Janvier, Le GenestSt-Isle, France) were used. These mice had free access to water and a standard chow diet and were kept with lights on from 07:00 until 21:00 hours. Experiments were reviewed and approved by the ethics committee of the Free University Brussels. The principles of laboratory animal care (NIH publication no. 85-23, revised 1985) were followed and specific national laws on this issue were complied with. The study was carried out in accordance with the Declaration of Helsinki as revised in 2000 .

Chemicals. Alloxan, rat gastrin I, recombinant human EGF and 5-bromo-2'-deoxyuridine were purchased from Sigma Chemical (St. Louis, Mo., USA). Proteinase K was obtained from Novocastra Laboratories (Newcastle, UK), ketamine from Ceva Sante Animale (Brussels, Belgium) and a mixture of medetomidine, methyl-parahydroxybenzoate and propyl-parahydroxybenzoate from Orion (Espoo, Finland). Formaldehyde (4\%) was purchased from Labonord (Templemars, France).

Primary antibodies. Rabbit polyclonal anti-cytokeratin was purchased from DAKO (Carpinteria, Calif., USA). Guinea pig polyclonal anti-insulin was a gift from Dr. C. Van Schravendijk [8]. Mouse monoclonal anti-bromodeoxyuridine (BrdU) was obtained from Cappel/Organon Teknika (WestChester, Pa., USA)

Design of experiments. Under light anaesthesia with ketamine $(75 \mathrm{mg} / \mathrm{kg})$ and a mixture of medetomidine, methyl-parahydroxybenzoate and propyl-parahydroxybenzoate $(1 \mathrm{mg} / \mathrm{kg})$, we made mice $(n=100)$ diabetic by intravenously injecting alloxan (dose: $70 \mathrm{mg} / \mathrm{kg}$ body weight at day 0) [9]. This dose was chosen because we found that $75 \%$ of mice exposed to this dose of alloxan could survive a follow-up period of at least one week without further treatment, while all surviving animals remained hyperglycaemic. At day 1,3 or 8 , the mice were anaesthetised with ketamine $(75 \mathrm{mg} / \mathrm{kg})$ and a mixture of medetomidine, methyl-parahydroxybenzoate and propyl-parahydroxybenzoate $(4 \mathrm{mg} / \mathrm{kg})$, and implanted intraperitoneally with Alzet osmotic minipumps (type 1007D, Charles River Laboratories, Wilmington, Mass., USA). These pumps release their content for approximately 7 days. The pumps contained gastrin I (release rate: $5.32 \mu \mathrm{g} / \mathrm{kg}$ body weight per hour) and/or EGF (release rate: $10 \mu \mathrm{g} / \mathrm{kg}$ body weight per hour). Gastrin was dis- solved in $8 \%$ dimethylsulfoxide in physiological saline. EGF was dissolved in $1 \mathrm{mmol} / \mathrm{l}$ acetic acid with $0.01 \% \mathrm{BSA}$ in physiological saline. We divided the mice into different groups, referred to in the text as follows: (i) control mice without alloxan treatment and without pump (control, $n=11$ ); (ii) mice with alloxan, without pump (alloxan-only, $n=37$ ); (iii) mice with alloxan and pump implanted one day after alloxan treatment (alloxan + pump, $n=41$ ); (iv) mice with alloxan and pump implanted 3 days after alloxan treatment (alloxan + pump*, $n=10$ ); (v) mice with alloxan and pump implanted 8 days after alloxan treatment (alloxan + pump**, $n=12$ ); and (vi) mice without alloxan treatment but with pump (pump-only, $n=6$ ). The mice were killed at different time points: 1,4 and 8 days, and 6 weeks after alloxan treatment. The alloxan + pump* mice were killed 10 days after alloxan treatment, the alloxan + pump $^{* *}$ mice 15 days after alloxan. In the group of mice with a follow-up up to 6 weeks after alloxan treatment we removed the pumps with EGF and gastrin under surgical anaesthesia at the end of the first week. So, in all animals the treatment lasted at the most for one week.

At different time points we measured non-fasting blood glucose concentrations in the tail vein with Glucocard Memory strips (A. Menarini Diagnostics, Florence, Italy). This was done between 9:00 a.m. and noon. We placed mice in the following categories according to blood glucose concentrations: normoglycaemic (4-9 $\mathrm{mmol} / \mathrm{l}$ ); hypoglycaemic (less than $4 \mathrm{mmol} / \mathrm{l})$; mildly hyperglycaemic (9-17 mmol/l); severely hyperglycaemic (above $17 \mathrm{mmol} / \mathrm{l}$ ). When the glucose concentrations were above the device's detection limit and the device displayed "high", it was scored as $33.31 \mathrm{mmol} / \mathrm{l}$. At day 8 we exposed the mice to a glucose tolerance test. This consisted of an intraperitoneal injection of a bolus of $3 \mathrm{~g}$ glucose per $\mathrm{kg}$ bodyweight after a 2 -h fast period. Blood glucose concentrations were then measured after $15 \mathrm{~min}$, and each $30 \mathrm{~min}$ for $2 \mathrm{~h}$. We registered the development of body weight and presented it as a percentage of initial body weight. One hour before killing the mice we injected BrdU intraperitoneally (60 mg/kg body weight), subsequently dissecting the pancreata and processing them for immunohistochemistry and insulin extraction.

Immunohistochemistry and analysis of double-positive cells. We fixed the pancreata in formaldehyde for $4 \mathrm{~h}$, dehydrated and embedded them in paraffin. Sections of $4 \mu \mathrm{m}$ were cut and stained with the avidin biotin complex technique [10]. We stained sections for insulin to evaluate beta-cell mass. To analyse proliferation, sections were double-stained for BrdU and wide-spectrum cytokeratin [10], or BrdU combined with insulin. To determine the BrdU labelling index, we analysed at least 1000 cytokeratin-positive cells, and at least 500 insulinpositive cells per mouse. For cytokeratin and BrdU staining, we did antigen retrieval by means of proteinase K-treatment $\left(15 \mu \mathrm{g}\right.$ per $\mathrm{ml}$ for $25 \mathrm{~min}$ at $\left.37^{\circ} \mathrm{C}\right)$. To analyse transitional phenotypes, we applied double immunofluorescence for the detection of insulin and cytokeratin. Secondary antibodies directly coupled to tetramethyl rhodamine isothiocyanate or fluorescein isothiocyanate were purchased from Jackson ImmunoResearch Laboratories (West Grove, Pa., USA). The percentages of cells with insulin and cytokeratin co-expression were estimated, as well as the percentage of islets in which such cells were detected. Between 1000 and 2500 cells were considered.

Analysis of beta-cell mass, islet density and beta-cell size. To estimate beta-cell mass, we used computer-assisted stereological morphometry to measure the insulin-positive area relative to the whole pancreatic section area. We analysed an area of at least $10 \mathrm{~mm}^{2}$ for each mouse. Beta-cell mass was calculated by 
a

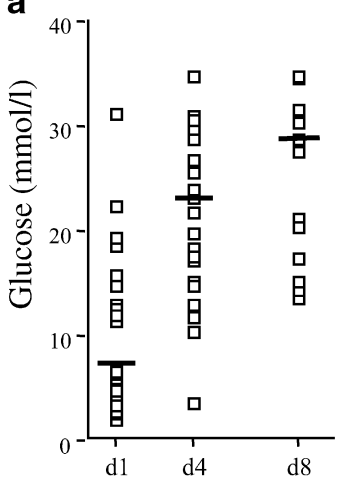

b

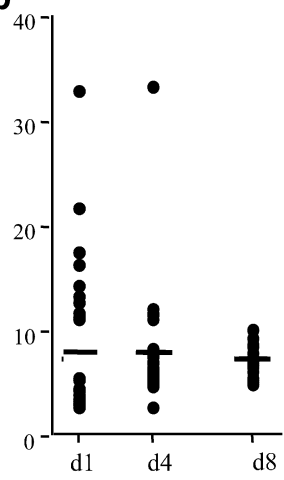

Fig. 1a, b. A follow-up of blood glucose concentrations $(\mathrm{mmol} / \mathrm{l})$ for each individual mouse ( $n=76$ in total) until mice were killed (day 1, 4 or 8). Open squares (a) represent alloxanonly mice ( $n=30$ on day $4 ; n=21$ on day 8 ). Filled circles (b) represent alloxan + pump mice $(n=32$ on day $4, n=24$ on day $8)$. Horizontal bars represent the mean values. $d 1$ day $1 ; d 4$ day 4; $d 8$ day 8

multiplying the relative insulin-positive tissue area by the corresponding pancreatic weight as described previously [5, 11]. We calculated islet density by scoring the number of clusters of at least five undamaged insulin positive cells per $10 \mathrm{~mm}^{2}$ tissue. Analyses were done blind.

Pancreatic insulin content. After acid insulin extraction, ultrasonic disintegration and centrifugation we measured pancreatic insulin content using a radio-immunoassay for rat insulin as described before [8]. Results were expressed relative to values in the pancreata of control mice.

BrdU pulse and chase labelling. BrdU $(60 \mathrm{mg} / \mathrm{kg})$ was injected intraperitoneally twice daily on the second and third day after pump implantation. The mice were killed $12 \mathrm{~h}$ after the pulse period or on day 8 after pump implantation, i.e. at the end of the chasing. BrdU incorporation was scored in approximately 500 insulin-expressing cells per sample, and in 1000 extra-islet cytokeratin-expressing cells. If fewer insulin cells were present at the end of the pulse period, this could be considered as evidence that the regeneration process was still in its initial phase.

Statistics. Results are expressed as means \pm SEM. We analysed the data with the Student's $t$ test and Mann-Whitney test. A $p$ value of less than 0.05 was considered to be statistically significant.

\section{Results}

Effect on blood glucose of combined gastrin and EGF therapy after alloxan treatment. Control (untreated) mice had blood glucose concentrations of $6.38 \pm 0.17 \mathrm{mmol} / \mathrm{l}(n=11)$. Of all alloxan-treated mice on day 1 (alloxan-only, and alloxan + pump), $48 \%$ had hypoglycaemia 1 day after alloxan treatment, 24\% were normoglycaemic, $20 \%$ mildly hyperglycaemic and $8 \%$ severely hyperglycaemic. By day $8,24 \%$ of the mice without further treatment (alloxan-only, Fig. 1a) were mildly hyperglycaemic and $76 \%$ were

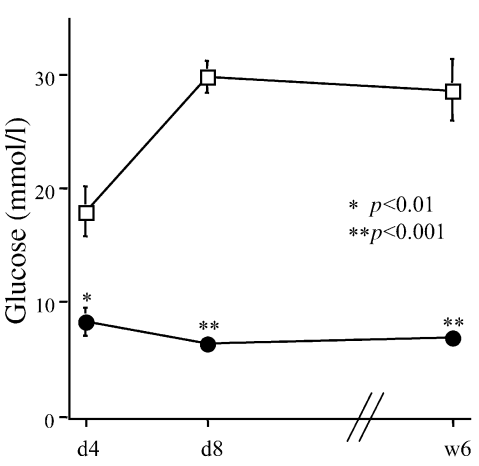

Fig. 2. Blood glucose concentrations $(\mathrm{mmol} / \mathrm{l})$ at the time mice were killed and histological analysis of the subgroups was performed. Open squares represent alloxan-only mice $(n=12$ on day $4, n=13$ on day $8, n=4$ on week 6 after alloxan), filled circles represent alloxan + pump mice $(n=8$ on day $4, n=14$ on day $8, n=9$ on week 6 after alloxan). $* p<0.01, * * p<0.001 . d 4$ day $4 ; d 8$ day $8 ; w 6$ week 6

severely hyperglycaemic. The mean blood glucose concentration at day 8 in this group was $27.26 \pm 1.67$ $\mathrm{mmol} / \mathrm{l}$. In the alloxan + pump group (Fig. 1b) all mice were normoglycaemic by day 8 , with mean blood glucose concentrations of $6.49 \pm 0.28 \mathrm{mmol} / \mathrm{l}$ (vs alloxan-only, $p<0.0001$ on day $4, p<0.001$ on day 8 ).

From each group of mice, we killed subgroups at different time points and did detailed histological analyses. Morphological examination of the other organs showed no signs of extra-pancreatic alloxan toxicity. Blood glucose concentrations in these mice at 4 days, 8 days and 6 weeks post-alloxan treatment (Fig. 2) were normoglycaemic and were lower in the alloxan + pump group than in the alloxan-only group, which showed persisting hyperglycaemia $(p<0.01$ on day 4 , $p<0.0001$ on day 8 and $p<0.0001$ on week 6 respectively).

Pumps filled with gastrin alone or EGF alone failed to generate similar results. After one week of gastrin only alloxan-exposed mice had blood glucose concentrations of $18.26 \pm 3.16 \mathrm{mmol} / \mathrm{l}(n=8)$. Alloxan-exposed mice with EGF only had $16.15 \pm 3.22 \mathrm{mmol} / \mathrm{l}(n=5)$. These concentrations were not significantly different from alloxan-only animals. Pump-only mice (no alloxan) had comparable blood glucose concentrations to control mice when analysed on day $8(6.05 \pm 0.22$ $\mathrm{mmol} / \mathrm{l}, n=6$ ).

Loss of body weight was mainly registered in the initial phase after alloxan treatment. Only at day 4 of analysis did loss of body weight tend to be less pronounced in the alloxan + pump group $(91 \pm 4 \%$ of initial weight, $n=7$ ) than in the alloxan-only group $(80 \pm 4 \%, n=12 ; p=0.051)$. At all other time points both groups had a similar profile. Although the pump (EGF + gastrin) did not restore body weight to the control level, body weight did not decline any further. Thus changes in appetite and food intake cannot explain the 

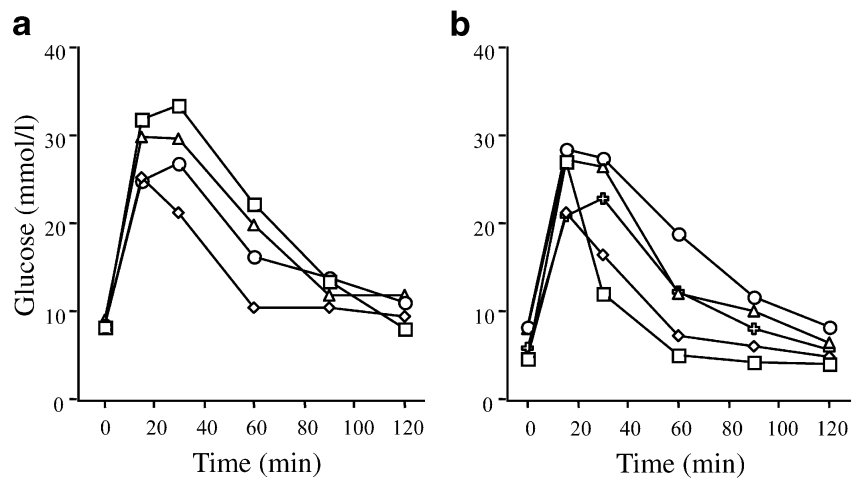

Fig. 3a, b. Glucose tolerance test after intraperitoneal glucose bolus. Blood glucose concentrations (mmol/l) during a 2-h follow-up period in (a) mice from the alloxan + pump group $(n=5)$ and $(\mathbf{b})$ in control mice $(n=4)$. Each symbol represents a single mouse

lower blood glucose concentrations in the alloxan + pump group.

Alloxan + pump mice that underwent a glucose tolerance test on day 8 had normalised blood glucose concentrations within the evaluation period of 120 min (Fig. 3a) and were comparable to the control mice (Fig. 3b). At all time points during the 2 hours after glucose stimulus, hyperglycaemic mice from the alloxan-only group had blood glucose concentrations above the detection limit.

Effects of alloxan and gastrin + EGF treatment on beta-cell mass and pancreatic insulin content. At day 1 after exposure to alloxan the relative insulin-positive tissue area in the mice dealt with in Fig. 2 was reduced to $0.51 \pm 0.09 \%$ (Fig. $4 \mathrm{a}$ ), where initially it was $1.08 \pm 0.24 \%$. In the alloxan-only group with persisting hyperglycaemia the relative insulin-positive tissue area at day 8 was $0.09 \pm 0.01 \%$ and at week $60.04 \pm$ $0.01 \%$. In alloxan + pump mice which were normoglycaemic this value was significantly higher $(p<0.01)$ at day 8 , i.e. $0.42 \pm 0.08 \%$. Even after the pump was removed, the relative beta-cell area remained at $0.39 \pm$ $0.07 \%$ in this group after 6 weeks $(p<0.01$ vs alloxanonly group). Mice in the pump-only group had a value of $0.83 \pm 0.47 \%(n=6)$, which was comparable to control mice.

As the pancreatic weight did not change over a one week period, the relative insulin-positive tissue area is a good indicator of beta-cell mass, which was $1.6 \pm 0.3 \mathrm{mg}$ in the alloxan + pump group, compared to $0.4 \pm 0.1 \mathrm{mg}$ in the alloxan-only mice $(p<0.01)$.

One day after alloxan treatment the number of islets per tissue area decreased to $33 \%(1.9 \pm 0.5$ per $\left.10 \mathrm{~mm}^{2}\right)$ of initial values in normal mice $(5.7 \pm 0.9$ per $10 \mathrm{~mm}^{2}$ ). This value was also significantly higher $(p<0.0001)$ in the alloxan + pump group than in the alloxan-only group at day $8(4.9 \pm 0.9$ vs $0.3 \pm 0.1$ per a

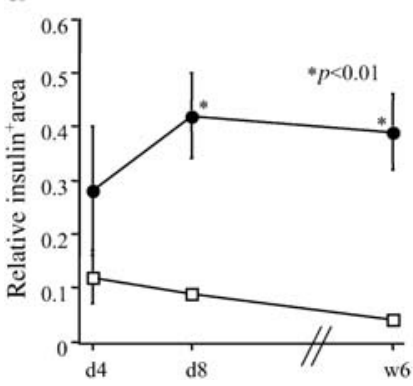

b

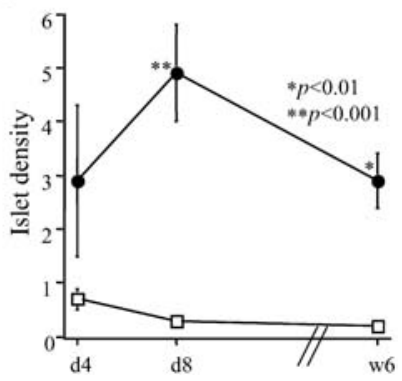

Fig. 4a, b. Histological analysis of development of the pancreatic beta-cell mass, expressed as (a) relative insulin-positive area (percentage) and (b) islet density (per $10 \mathrm{~mm}^{2}$ ). Open squares represent alloxan-only mice $(n=12$ on day $4, n=13$ on day $8, n=4$ on week 6 after alloxan), filled circles represent alloxan + pump mice ( $n=8$ on day $4, n=14$ on day $8, n=9$ on week 6 after alloxan). ${ }^{*} p<0.01,{ }^{* *} p<0.001$. d4 day 4 ; d8 day 8 ; w6 week 6

$\left.10 \mathrm{~mm}^{2}\right)$ and at week $6(2.9 \pm 0.5$ vs $0.2 \pm 0.1$ per $10 \mathrm{~mm}^{2} ; p<0.01$; Fig. 4b). In alloxan-only mice only $8 \pm 2 \%(n=9)$ of the pancreatic insulin content of control mice was left at day 8. Again, higher values $(p<0.0001)$ were noted in the alloxan + pump group $(123 \pm 21 \%, n=7)$.

Effects of implantation of a pump with gastrin and EGF after a longer period of disturbed glucose homeostasis. When pumps were implanted 3 days after alloxan treatment (alloxan + pump* group), blood glucose concentrations decreased from $23.4 \pm 2.9 \mathrm{mmol} / \mathrm{l}$ to $15.7 \pm 3.1 \mathrm{mmol} / \mathrm{l}$ within 4 days of EGF and gastrin therapy. No further lowering of blood glucose concentrations was noted (blood glucose values after one week of treatment: $15.6 \pm 2.6 \mathrm{mmol} / \mathrm{l}$ ) and mice remained mildly hyperglycaemic. At the moment the pump was implanted, the relative beta cell area was $0.12 \pm 0.05 \%$. After one week of EGF and gastrin treatment, the relative insulin area increased to $0.48 \pm 0.22$ $(p<0.01)$, an absolute increase in beta-cell mass from $0.4 \pm 0.2 \mathrm{mg}$ to $1.6 \pm 0.7 \mathrm{mg}$.

The alloxan + pump** group consisted of mice in which a pump was implanted at day 8 after alloxan treatment, and which were killed and analysed at day 15. In this group only 8 of 12 mice survived till day 15. Especially the severely hyperglycaemic mice failed to survive, apparently because of the anaesthesia and the surgical procedure of pump implantation. Thus the comparison with the alloxan-only group at day 8 is biased, as mainly mildly hyperglycaemic mice were available in the alloxan + pump** group.

These mildly hyperglycaemic mice with blood glucose concentrations of $15.82 \pm 2.28 \mathrm{mmol} / \mathrm{l} \quad(n=8)$ showed a reduction in blood glucose concentrations after treatment with EGF- and gastrin-filled pumps. By day 11 after alloxan treatment blood glucose concentrations were significantly reduced to a mean value 
of $7.88 \pm 0.94 \mathrm{mmol} / \mathrm{l}(p<0.01)$ and on the day these mice were killed (day 15 after alloxan treatment) blood glucose concentrations were $9.10 \pm 0.94 \mathrm{mmol} / \mathrm{l}$ $(p<0.01)$. At day 15, histological analysis showed that the insulin immunoreactive area was $0.26 \pm 0.08 \%$, whereas in alloxan-only mice at day 8 the value was $0.09 \pm 0.01 \%(p<0.05)$. Islet density was $2.6 \pm 0.8$ per $10 \mathrm{~mm}^{2}$ in the alloxan + pump** group versus $0.4 \pm 0.1$ per $10 \mathrm{~mm}^{2}$ in the alloxan-only group $(p<0.01)$. Pancreatic insulin content was significantly higher in the former $(p<0.01 ; 52.5 \pm 14.2 \%$ of control pancreata), whereas it was reduced to $8 \pm 2 \%$ in alloxan-only mice analysed on day 8 .

Effects of EGF + gastrin therapy on pancreatic cell proliferation and neogenesis of insulin-producing cells. We did not detect differences in the BrdU labelling index of insulin positive-cells between the alloxan + pump group $(0.2 \pm 0.1 \%, n=5)$ and the control mice $(0.2 \pm 0.1 \%, n=5)$. The beta cell count was insufficient in the alloxan-only group, because most beta cells had been destroyed. However, the BrdU labelling index of exocrine duct cells was higher in the alloxan + pump group $(1.5 \pm 0.1 \%, n=8)$ than in the alloxan-only group $(0.4 \pm 0.1 \%, n=10 ; p<0.01)$. The value in the alloxan-only group was also higher than in control mice $(0.2 \pm 0.1 \%, n=5 ; p<0.05)$. In the pump-only group, the duct-labelling index was also increased $(1.5 \pm 0.4 \%, n=5 ; p<0.01)$ and comparable to the alloxan + pump group. We noted regional differences in the proliferative response of the duct cells, and that in some pancreatic lobes the response was higher than in others. In control mice no regional differences were observed.

We identified cells that were double-positive for duct-type cytokeratin and insulin in the larger ducts, however at a low frequency. These were also seen in the control mice. In contrast, we frequently observed cells co-expressing cytokeratins and insulin in alloxan + pump mice, especially after 4 days (Fig. 5). In pancreata in the control group and in the alloxan + pump group when analysed at day 4 and day 8 respectively $3 \%, 65 \%$ and $35 \%$ of the islets contained insulin-positive cells co-expressing cytokeratin. Of all insulinpositive cells $1 \%, 65 \%$ and $4 \%$ respectively showed co-expression with cytokeratin. Co-expression was found in islets, in single cells and in ducts. These endocrine cells also expressed high levels of transcription factor Pdx-1 and GLUT-2. In the alloxan + pump group we also often encountered close associations between insulin-expressing islets and cytokeratin-positive ducts.

BrdU pulse and chase labelling. When BrdU was injected twice daily on the second and third day after pump implantation, the labelling indices in the cytokeratin-positive cells were $2.6 \pm 1.2 \%(n=4)$ when analysed after the chase period, whereas $4.0 \pm 1.3 \%(n=4)$
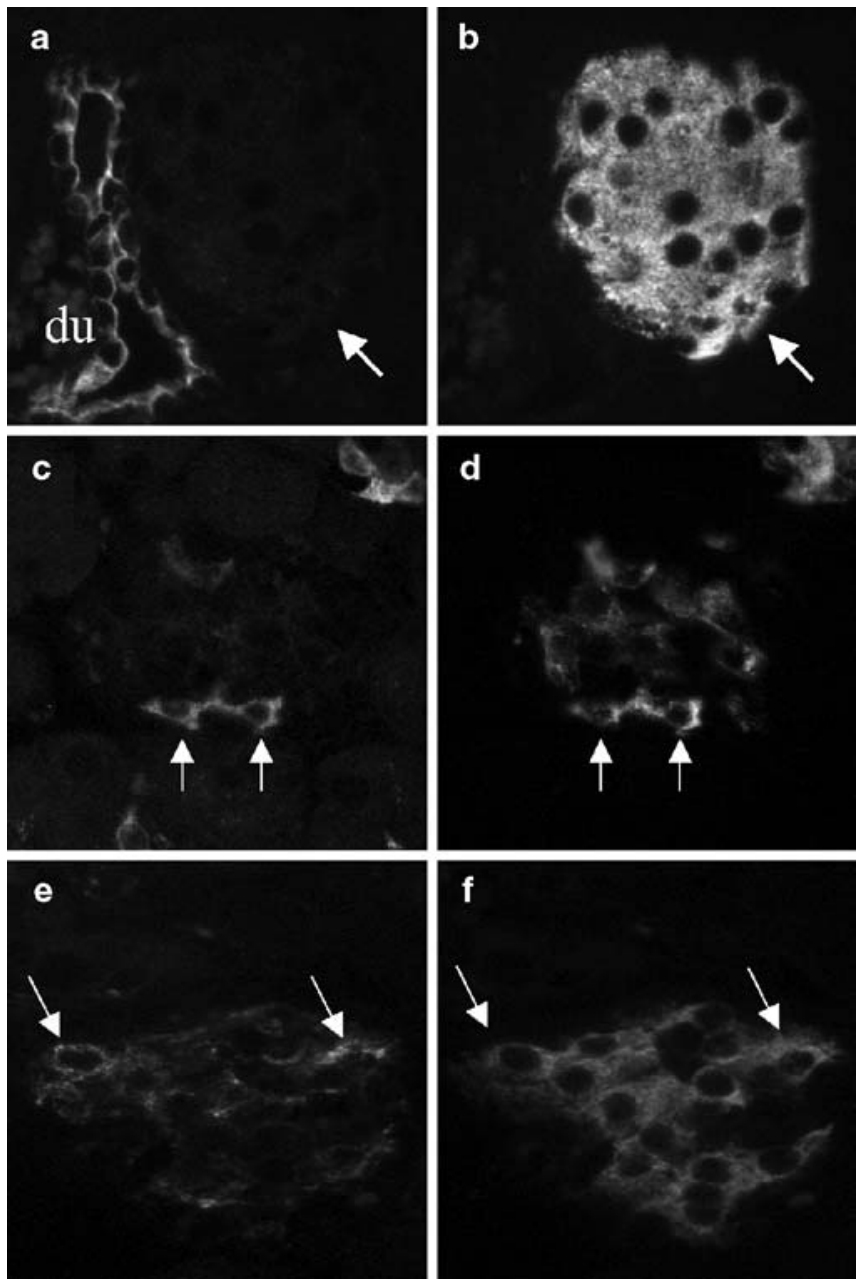

Fig. 5a-f. Double immunofluorescence staining for insulin $(\mathbf{b}, \mathbf{d}, \mathbf{f})$ and cytokeratin $(\mathbf{a}, \mathbf{c}, \mathbf{e})$ in untreated control pancreas $(\mathbf{a}, \mathbf{b})$ and pancreas from the alloxan $+\operatorname{pump}$ group $(\mathbf{c}, \mathbf{d}, \mathbf{e}, \mathbf{f})$, analysed at day 4 . Note that cytokeratin was not found in normal islet cells (a, b), whereas islet cells were cytokeratin-positive at day $4(\mathbf{c}, \mathbf{d}, \mathbf{e}, \mathbf{f})$. The arrows point to some of the islet cells. Bar=15 $\mu \mathrm{m}$. $d u$ duct

were labelled after the pulse period. After the chase period the percentage of BrdU-expressing beta cells was $1.5 \pm 0.5 \% \quad(n=4)$, which is significantly more $(p<0.05)$ than after the pulse period (percentage of insulin-cells incorporating the label: $0.2 \pm 0.1 \% ; n=4)$.

\section{Discussion}

Our study showed a complete normalisation of blood glucose concentrations in adult mice with toxin (alloxan)-mediated beta-cell destruction after treatment with two soluble factors, namely EGF and gastrin for one week. The alloxan dose used in this study induced an irreversible hyperglycaemic state in all mice not given further treatment, as previously shown [9]. One day after alloxan treatment the mice had a broad range of blood glucose concentrations, from hypoglycaemic to 
severely hyperglycaemic. The observed hypoglycaemia was probably due to sudden and massive destruction of pancreatic beta cells. For all factors that were further analysed, no differences were noted according to this initial blood glucose score. Alloxan-treated mice implanted one day after alloxan treatment with a pump containing EGF and gastrin became normoglycaemic 4 days after the alloxan treatment. The effect lasted for at least 6 weeks (which was the end point of our study), also when the pump had been removed after one week.

The diabetogenic effect of alloxan was also reflected in a diminished beta-cell mass. However, when pumps were implanted the day after alloxan treatment, dead beta cells were still present and were insulin immunoreactive, so the beta-cell mass at the start of treatment could not be measured reliably. It is possible that the beneficial effect of the treatment seen in this study resulted from a combination of islet neogenesis and islet-cell protection from alloxan damage. Alloxan is a potent generator of reactive oxygen species, which mediate beta-cell toxicity [10].

The results obtained when the treatment was started 3 days after alloxan treatment showed that there was a significantly increased beta-cell mass after one week of treatment. This proves that neoformation of islets occurred. We also noted a beneficial effect of EGF and gastrin on blood glucose concentrations and betacell mass when given one week post-alloxan. However, these observations are somewhat biased because only mildly hyperglycaemic animals survived the implantation. In addition to the effect on neogenesis, it cannot be ruled out that EGF and gastrin treatment had a protective effect on remaining beta cells, especially in animals in which treatment started one day after alloxan. This would explain the better improvement in blood glucose concentrations observed in the latter group.

The total pancreatic insulin content of the alloxan + pump mice was similar to that in normal mice, suggesting that the amount of insulin per beta cell (granulation) was higher than normal. This could account for the normal glucose values despite a lower number of beta cells. Clinical reports suggest that before diagnosis Type 1 diabetes patients were able to control glycaemia with a sub-optimal insulin-producing cell mass [11]. Incomplete restoration of the islet cells could be due to the fact that once blood glucose concentrations can be controlled efficiently, the stimulus for further increase is lost. In our experiments the mice treated with EGF and gastrin had normalised blood glucose concentrations within $2 \mathrm{~h}$ of an intraperitoneal glucose bolus, a similar result to that observed in control mice.

Other indications that treatment with EGF and gastrin stimulates islet neogenesis were the increased tissue density of islet structures, and, indirectly, the appearance of "transitional" cells co-expressing duct- type cytokeratins and insulin. According to the literature, different cell types in different models could contribute to regeneration in the pancreas [12]. Our data suggest that in the present model duct cells are involved. Normally, cytokeratin staining is specific for duct cells, and islet cells are not stained for cytokeratins except for fetal development and during regeneration [13]. Whereas insulin-positive cells co-expressing cytokeratins were rare in normal pancreas, they were frequently observed in the alloxan- treated pancreas a few days after therapy with EGF and gastrin. After one week of treatment, the number of islets with double positive cells and the number of such cells per islet was decreased. On the other hand, after the BrdU chase period in alloxan + pump mice (day 8) significantly more insulin-cells were labelled than shortly after the BrdU injections. This means that beta cells differentiated from cells that actively incorporated the label during the pulse period. The percentage of labelled cytokeratin-cells was decreased during the chase-period, which is probably due to dilution of the label after multiple divisions and/or differentiation of the duct cells into the insulin-expressing phenotype. BrdU pulse labelling at the end of the EGF plus gastrin treatment in alloxan + pump mice showed significant stimulation of the proliferation of cytokeratinpositive duct cells, while beta-cell proliferation remained very low in all conditions. In pump-only mice increased duct cell proliferation was also found, but there was no neoformation of beta cells. This indicates that besides EGF and gastrin treatment as yet unidentified factors are involved in generating the right condition for beta-cell differentiation from the progenitors. Together these data suggest that proliferating cytokeratin-positive cells can differentiate into beta cells via a transitional state with low cytokeratin and insulin expression. As transdifferentiation from acinar to duct cells and vice versa has been shown before [6, 14] and an increase in acinar cell proliferation was found here, it cannot be ruled out that apart from duct cells, acinar cells also participate in the regeneration process.

For blood glucose concentrations to normalise a combination of both factors was essential, as the results could not be duplicated with gastrin alone or EGF alone. After duct-ligation, gastrin alone was sufficient to stimulate neogenesis [5], but it has been shown that endogenous TGF- $\alpha$ expression is induced in the ligated tissue [15]. Other investigators have also suggested that the EGF family and its receptors play a role in islet differentiation in fetal pancreas development $[16,17]$ and in the IFN- $\gamma$ mouse model for neogenesis [18]. Furthermore, together with activin A, endocrine differentiation of an exocrine cell-line was induced by betacellulin, another member of the EGFfamily [19]. Gastrin is reported to be expressed specifically in the pancreas during a crucial period for fetalislet differentiation [20]. Whereas we are presenting 
evidence of beneficial effects of gastrin, it has also been reported that gastrin/CCK receptor antagonists worsen the diabetogenic effects of a similar dose of alloxan in mice [21], which is consistent with our results.

In studies with a similar focus, glucagon-like peptide- 1 therapy attenuated diabetes in the partial pancreatectomy model [22], but in the neonatal streptozotocin model no normal glucose responsiveness was achieved, despite the increase in beta-cell mass [23]. In a model of selective alloxan perfusion, betacellulin was reported to induce beta-cell neogenesis and improve glucose tolerance, but this effect could not be obtained before 8 weeks of treatment [24]. The approach outlined in our paper relies on the endogenous regenerative capacity of the diabetic pancreas. This model of islet neogenesis could be useful in unravelling the underlying neogenic mechanisms and further identifying the islet precursor cells in other strains and transgenic mice. The model has a number of advantages over previously described regeneration models like duct ligation or partial pancreatectomy, where the treatment also induces major histological changes like exocrine tissue damage, inflammation and fibroplasia.

Acknowledgements. This work was supported by a Focused Research Grant from the European Foundation for the Study of Diabetes, Juvenile Diabetes Research Foundation and Novo Nordisk. Additional support was obtained from the Fund for Scientific Research-Flanders (FWO-grant G001502). I. Rooman is a post-doctoral research fellow from the Fund of Scientific Research-Flanders. A. Nuyts, E. De Blay and W. Rabiot are acknowledged for their skilful technical assistance. We are grateful to Dr D. Pipeleers for his general and logistic support.

\section{References}

1. Serup P, Madsen OD, Mandrup-Poulsen T (2001) Islet and stem cell transplantation for treating diabetes. BMJ 322:29-32

2. Pipeleers D, Keymeulen B, Chatenoud L et al. (2002) A view on beta cell transplantation in diabetes. Ann NY Acad Sci 958:69-76

3. Yamaoka T (2002) Regeneration therapy of pancreatic beta cells: towards a cure for diabetes? Biochem Biophys Res Commun 296:1039-1043

4. Bouwens L, Kloppel G (1996) Islet cell neogenesis in the pancreas. Virchows Arch 427:553-560

5. Rooman I, Lardon J, Bouwens L (2002) Gastrin stimulates beta-cell neogenesis and increases islet mass from transdifferentiated but not from normal exocrine pancreas tissue. Diabetes 51:686-690

6. Rooman I, Lardon J, Flamez D, SchuitF, Bouwens L (2001) Mitogenic effect of gastrin and expression of gastrin receptors in duct-like cells of rat pancreas. Gastroenterology 121:940-949

7. Wang TC, Bonner-Weir S, Oates PS et al. (1993) Pancreatic gastrin stimulates islet differentiation of transforming growth factor alpha-induced ductular precursor cells. J Clin Invest 92:1349-1356

8. Pipeleers DG, Veld PA in't, Van De Winkel M, Maes E, Schuit FC, Gepts W (1985) A new in vitro model for the study of pancreatic A and B cells. Endocrinology 117: $806-816$

9. Ahren B, Sundkvist G (1995) Long-term effects of alloxan in mice. Int J Pancreatol 17:197-201

10. Walde SS im, Dohle C, Schott-Ohly P, Gleichmann H (2002) Molecular target structures in alloxan-induced diabetes in mice. Life Sci 71:1681-1694

11. Atkinson MA, Maclaren NK (1994) The pathogenesis of insulin-dependent diabetes mellitus. N Engl J Med 331: 1428-1436

12. Zhang YQ, Sarvetnick N (2003) Development of cell markers for the identification and expansion of islet progenitors cells. Diabetes Metab Res Rev 19:363-374

13. Bouwens L, Braet F, Heimberg H (1995) Identification of rat pancreatic duct cells by their expression of cytokeratins 7, 19 and 20 in vivo and after isolation and culture. J Histochem Cytochem 43:245-253

14. Rooman I, Heremans Y, Heimberg H, Bouwens L (2000) Modulation of rat pancreatic acinoductal transdifferentiation and expression of PDX-1 in vitro. Diabetologia 43:907-914

15. Wang RN, Rehfeld JF, Nielsen FC, Kloppel G (1997) Expression of gastrin and transforming growth factor-alpha during duct to islet cell differentiation in the pancreas of duct-ligated adult rats. Diabetologia 40:887-893

16. Miettinen PJ, Huotari M, Koivisto T et al. (2000) Impaired migration and delayed differentiation of pancreatic islet cells in mice lacking EGF-receptors. Development 127:26172627

17. Cras-Meneur C, Elghazi L, Czernichow P, Scharfmann R (2001) Epidermal growth factor increases undifferentiated pancreatic embryonic cells in vitro: a balance between proliferation and differentiation. Diabetes 50:1571-1579

18. Arnush M, Gu D, Baugh C et al. (1996) Growth factors in the regenerating pancreas of gamma-interferon transgenic mice. Lab Invest 74:985-990

19. Sumi S, Tamura K (2000) Frontiers of pancreas regeneration. J Hepatobiliary Pancreat Surg 7:286-294

20. Larsson LI, Rehfeld JF, Sundler F, Hakanson R (1976) Pancreatic gastrin in foetal and neonatal rats. Nature 262: 609-610

21. Parmar NS, Tariq M, Ageel AM (1987) Proglumide, a cholecystokinin receptor antagonist, exacerbates alloxaninduced diabetes mellitus in Swiss mice. J Pharm Pharmacol 39:1028-1030

22. Xu G, Stoffers DA, Habener JF, Bonner-Weir S (1999) Exendin-4 stimulates both beta-cell replication and neogenesis, resulting in increased beta-cell mass and improved glucose tolerance in diabetic rats. Diabetes 48:22702276

23. Tourrel C, Bailbe D, Meile MJ, Kergoat M, Portha B (2001) Glucagon-like peptide-1 and exendin-4 stimulate beta-cell neogenesis in streptozotocin-treated newborn rats resulting in persistently improved glucose homeostasis at adult age. Diabetes 50:1562-1570

24. Yamamoto K, Miyagawa J, Waguri M et al. (2000) Recombinant human betacellulin promotes the neogenesis of betacells and ameliorates glucose intolerance in mice with diabetes induced by selective alloxan perfusion. Diabetes 49:2021-2027 